\title{
COMPLICATED PYELONEPHRITIS AND PYONEPHROSIS CAUSED BY SALMONELLA TYPE C: CASE REPORT
}

I.J. Bercholc-Urinowsky ${ }^{1}$, P. Figueroa-Arnal2 ${ }^{2}$, D. Qaraen-Saloani², L. Berkun², G. Hidas ${ }^{3}$, A.M. Simckes ${ }^{4}$, O. Volovelsky ${ }^{5}$, D. Averbuch ${ }^{5}$

${ }^{1}$ Mexican Oil Company High Specialty Medical Center, Pediatrics, Mexico City, Mexico. ${ }^{2}$ Hadassah-Hebrew University Medical Center, Pediatrics, Jerusalem, Israel. ${ }^{3}$ Hadassah-Hebrew University Medical Center, Pediatric Urology, Jerusalem, Israel. ${ }^{4}$ Hadassah-Hebrew University Medical Center, Pediatric Nephrology, Jerusalem, Israel ${ }^{5}$ Hadassah-Hebrew University Medical Center, Pediatric Infectious Diseases, Jerusalem, Israel.

\section{Background}

Salmonella species are considered a rare cause of UTI in children, usually associated with immunocompromised state or anatomic abnormalities.

We present a case of a 14 month old boy with urosepsis and pyonephrosis caused by Salmonella Group C.

\section{Case Description}

A 14 month old boy previously healthy presented to the emergency department with a 5-day history of weakness, fever $\left(40.5^{\circ} \mathrm{C}\right)$, vomiting and diarrhea.

Before admission, he was diagnosed with suspected bacterial gastroenteritis and was treated empirically with azithromycin, without improvement.

At admission, urinalysis detected pyuria with moderate blood and microalbuminuria (table 1). Blood, feces and urine cultures yielded Salmonella enterica group $\mathrm{C}$.

Abdominal US revealed moderatesevere left hydrouretheronephrosis and pyonephrosis (figure 1 and 2).

Congenital obstructive megaureter was diagnosed.

\section{Case Description (cont.)}

He was treated with ceftriaxone and subsequent blood, urine and stool cultures were all negative.

An ureteral stent was inserted for drainage and within a few hours his symptoms improved dramatically.

Treatment with oral trimethoprimsulfamethoxazole was added.

A left ureteral reimplantation surgery was performed to correct congenital obstructive megaureter secondary to ureteral vesicular junction stenosis. Follow up abdominal US with improvement of hydronephrosis.

\begin{tabular}{|l|l|l|}
\hline \multicolumn{2}{|c|}{ Table 1. Urinalysis at Admission } \\
\hline & \multicolumn{1}{|c|}{ Result } & \multicolumn{1}{|c|}{ Ref Range } \\
\hline Glucose & Negative & Negative \\
\hline Trichomonas & & $0-100$ \\
\hline Keton & Negative & Negative \\
\hline Specific gravity & 1.010 & $1.01-1.02$ \\
\hline Blood & Moderate & Negative \\
\hline PH & 6 & $6-7$ \\
\hline Protein & 30 & Negative-100 \\
\hline Urobilinogen & 0.2 & $1-2$ \\
\hline Nitrites & Negative & Negative \\
\hline Leucocytes & Large & Negative \\
\hline
\end{tabular}

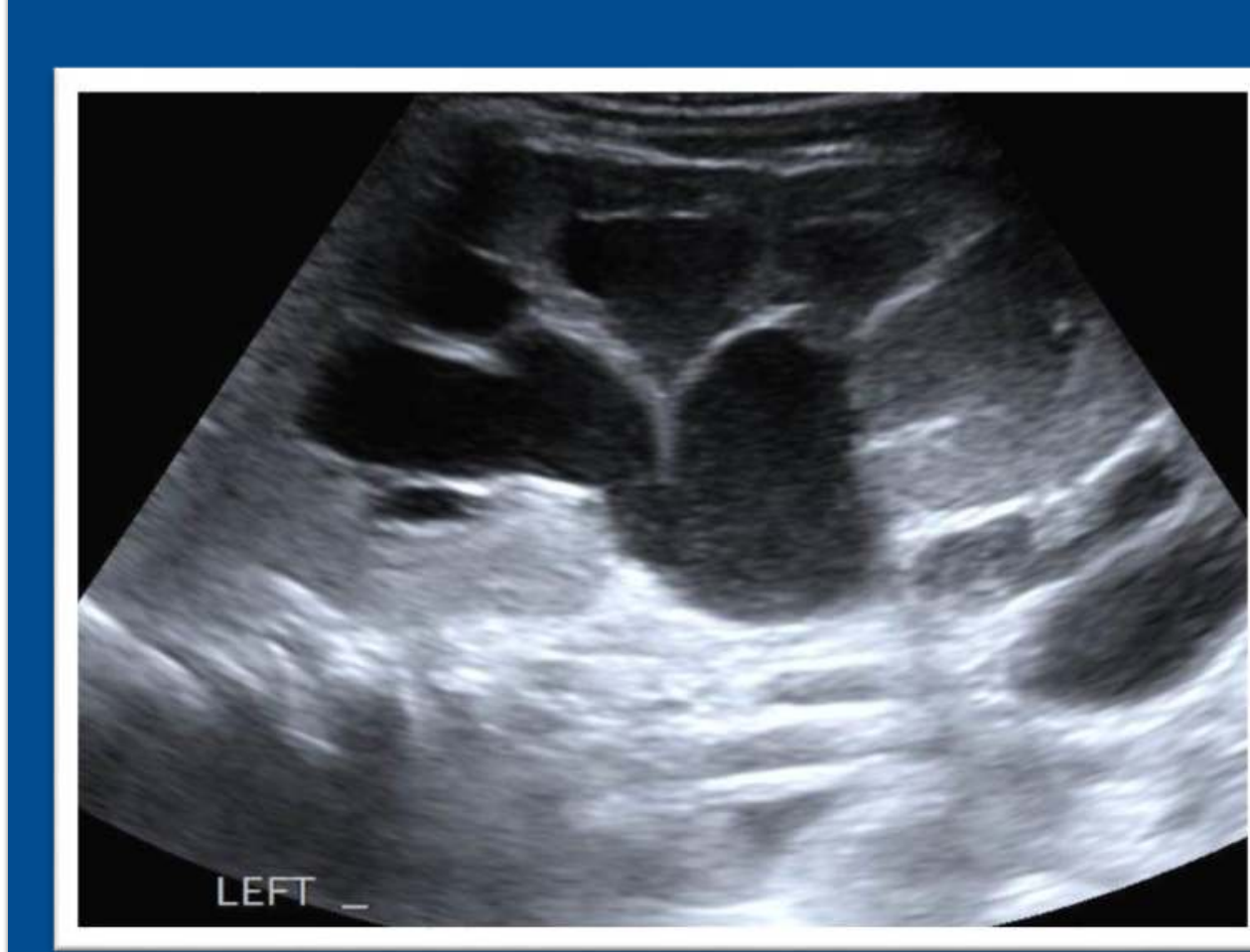

Figure 1. Abdominal US, left kidney with dilated calyces and pelvis filled with echogenic material

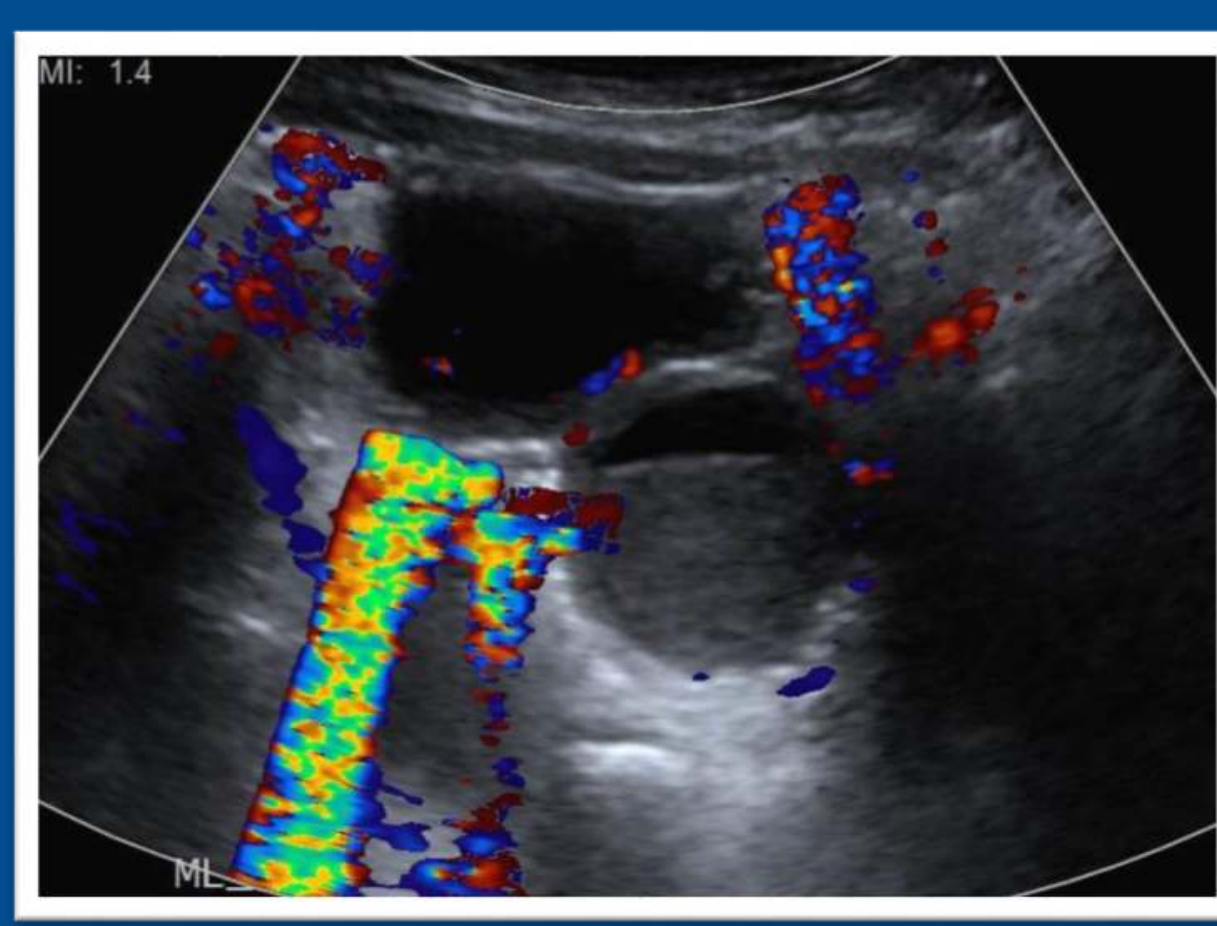

Figure 2. Abdominal US, ureter filled with purulent material 